\title{
Os requisitos para empréstimos do BNDES e sua influência no desenvolvimento
} econômico

\author{
The requirements for BNDES loans and its influence on economic development
}

\author{
Emerson Ademir Borges de Oliveira* \\ Catharina Martinez Heinrich Ferrer ${ }^{* *}$ \\ Heverton Lopes Rezende ${ }^{* * *}$
}

\section{REFERÊNCIA}

FERRER, Catharina; OLIVEIRA, Emerson; REZENDE, Heverton. Os requisitos para empréstimos do BNDES e sua influência no desenvolvimento econômico. Revista da Faculdade de Direito da UFRGS, Porto Alegre, n. 47, p. 201-220, dez. 2021. DOI: https://doi.org/10.22456/0104-6594.107650.

\section{RESUMO}

O Banco Nacional do Desenvolvimento Econômico e Social é o maior banco de desenvolvimento brasileiro, criado em 1952 pelo Presidente Getúlio Vargas com a finalidade de fomentar o crescimento do país, por meio de empréstimos com retorno de médio e longo prazo. Os recursos financeiros do banco são compostos por diversas fontes, dentre elas, aportes do Tesouro Nacional. O objetivo da pesquisa é apresentar os requisitos para a concessão de empréstimos pelo BNDES, bem como fazer uma breve explanação sobre seu impacto no desenvolvimento econômico. Por meio do método dedutivo, pesquisa bibliográfica e análise de dados secundários de fontes oficiais, foram apresentados os requisitos para a concessão de empréstimos, bem como fatores impeditivos para que a operação de crédito seja autorizada. Por fim, foram apresentados resultados de pesquisas feitas por diversos autores, incluindo o relatório de efetividade do BNDES, de 2017, que indica que para cada um milhão aplicado pelo banco em atividades com alta influência sobre o emprego, foram estimados 20,2 postos de trabalho associados à sua implementação, embora esse resultado não seja comum a todos os seguimentos da economia. Ainda assim, pode-se concluir que o BNDES cumpre sua função social.

\section{PALAVRAS-CHAVE}

Banco de desenvolvimento. BNDES. Requisitos para empréstimos. Função social.

\begin{abstract}
The National Bank for Economic and Social Development is the largest Brazilian development bank, created in 1952 by President Getulio Vargas with the purpose of promoting the country's growth through medium and longterm loans. The bank's financial resources are composed of several sources, among them, contributions from the National Treasury. The objective of the research is to present the requirements for the granting of loans by the BNDES, as well as to make a brief explanation about its impact on economic development. Through the deductive method, bibliographic research and analysis of secondary data from official sources, the requirements for the granting of loans were presented, as well as impeding factors for the credit operation to be authorized. Finally,
\end{abstract}

\footnotetext{
* Pós-Doutor em Democracia e Direitos Humanos pela Universidade de Coimbra. Doutor e Mestre em Direito do Estado pela Universidade de São Paulo. Coordenador-Adjunto e Professor Permanente do Programa de Mestrado e Doutorado em Direito da Universidade de Marília. Advogado e parecerista.

** Doutoranda e Mestre em Direito pela Universidade de Marília. Advogada.

*** Doutorando em Direito pela Universidad del Museo Social Argentino. Mestre em Direito pela Universidade de Marília. Especialista em Direito Constitucional pela Faculdade Única de Ipatinga. Especialista em Direito Civil e Processo Civil pela AVM Faculdade Integrada. Especialista em Direito Público pela Universidade Gama Filho. Analista Judiciário do Tribunal de Justiça do Estado do Mato Grosso.
} 
research results by several authors were presented, including the 2017 BNDES effectiveness report, which indicates that for every one million invested by the bank in activities with a high influence on employment, an estimated 20.2 jobs were associated with its implementation, although this result is not common to all segments of the economy. Even so, it can be concluded that the BNDES fulfills its social role.

\section{KEYWORDS}

Development bank. BNDES. Loan requirements. Social role.

\section{SUMÁRIO}

1. Introdução. 2. Os bancos e o crédito no Brasil. 2.1. Bancos de Desenvolvimento e o BNDES. 2.2 O Banco Nacional de Desenvolvimento Econômico e Social (BNDES). 2.3 Fiscalização do BNDES. 2.4 Fontes de recursos do BNDES. 3 Os requisitos para a concessão de empréstimos pelo BNDES. 3.1 Cartão BNDES. 4. Algumas considerações sobre o impacto do BNDES no desenvolvimento. 5. Conclusão. Referências. Dados de publicação.

\section{INTRODUÇÃO}

Em razão da oferta de empréstimos de médio e longo prazo, os bancos de desenvolvimento em âmbito estadual e nacional desempenham importante função no desenvolvimento econômico em sua área de abrangência.

O maior banco de desenvolvimento brasileiro é o Banco Nacional de Desenvolvimento Econômico e Social (BNDES), que foi criado em 1952 para fomentar diversos setores da economia, auxiliando o país a se desenvolver.

Sendo assim, concede empréstimos de recursos financeiros a empresas brasileiras em condições mais vantajosas que as praticadas no mercado; além de apoiar programas, projetos, obras e serviços que se relacionem com o desenvolvimento econômico e social.

É nesse contexto que o presente artigo, por meio do método dedutivo, pesquisa bibliográfica e análise de dados secundários e de fontes oficiais, pretende-se responder ao seguinte problema: no contexto atual, é possível afirmar que a concessão desses empréstimos pelo BNDES seguem critérios objetivos e com foco diretamente relacionado ao desenvolvimento econômico do País?

Para tanto, propõe-se como objetivo geral: relacionar os principais requisitos para a concessão de empréstimos junto ao BNDES e constatar uma possível relação desses aportes com o desenvolvimento econômico; e como objetivos específicos: a) indicar sua fonte de captação de recursos, bem como seus mecanismos de controle e fiscalização; b) discorrer sobre os critérios para escolha dos beneficiários pelas operações.

Justifica-se a pesquisa em razão da relevância do tema, que envolve a ordem econômica estabelecida no art. 170 da Constituição da República Federativa do Brasil, a resposta ao problema indicado certamente contribuirá para disseminar a importância do banco para o desenvolvimento do País. 


\section{OS BANCOS E O CRÉDITO NO BRASIL}

Como se sabe, os bancos, espécie do gênero instituição financeira, são "intermediários do dinheiro", pois captam recursos no mercado e repassam aos seus clientes em operações de crédito, onde o lucro da instituição comumente é obtido por meio do spread e dos juros do mutuário (TIMM, 2001, p. 227).

Normalmente, são muito elevadas as taxas cobradas por essas instituições, ao realizar operações relacionadas a empréstimos bancários. Se, por um lado, o Brasil é um mercado atrativo para os bancos, por outro lado as taxas elevadas podem desestimular a procura e obtenção de crédito, e consequentemente impactando de forma negativa o desenvolvimento econômico.

Uma crítica a postura dos bancos no Brasil é apresentada por Ataíde e Soares (2017, p. 74):

[n]o Brasil, a situação ainda é mais preocupante por causa das altas taxas de juros na utilização dos cartões de crédito, conhecido por ter o maior spread Bancário. As instituições financeiras e econômicas veem no cartão de crédito um serviço altamente lucrativo, grande parte em razão da regulação pouco rigorosa com o setor (viés mercadológico da regulação) e da ausência de sanções efetivas nos casos de descumprimento, somados à falta de fiscalização desses serviços. Neste contexto questiona-se quais estímulos teriam os fornecedores de crédito em adotar práticas mais responsáveis?

Ataíde e Soares (2017, p. 74) salientam que a justificativa apresentada para a cobrança das taxas de juros das tão altas no Brasil se relacionam ao "risco do negócio", já que o não pagamento do empréstimo é uma prática recorrente; e por não haver uma sanção específica "in casu”, a margem de lucro deve se vincular a um patamar mais atraente aos bancos, o que, por vezes, a torna abusiva.

É nessa seara que os bancos públicos de desenvolvimento surgem como uma alternativa aos empreendedores, pois ofertam crédito mediante taxas mais acessíveis e personalizadas a cada seguimento, estimulando o setor produtivo. Vejamos a seguir.

\subsection{BANCOS DE DESENVOLVIMENTO E O BNDES}

Inicialmente destaca-se que os bancos públicos podem ter diversas funções, como bancos comerciais, bancos de desenvolvimento, bancos postais, entre outros. "Instituições relevantes para o desenvolvimento nacional de inúmeros países, bancos públicos possuem peso relativo 
expressivo no total de assets dos sistemas bancários nacionais dos países". (ARAÚJO; BACELETTE, 2018, p. 49).

Nesse sentido:

\begin{abstract}
Esses bancos podem desempenhar múltiplas funções, abrangendo desde microcrédito e microfinanças orientados à inclusão social, passando por bancos semicomerciais e financiadores de projetos estruturantes de longo prazo - ainda que realizado por instituições híbridas -, tais como: instalação e recapacitação de infraestrutura; desenvolvimento de tecnologias críticas, cujos investimentos podem levar décadas para atingir maturação; agricultura comercial ou de subsistência; habitação; entre outros. (ARAÚJO; BACELETTE, 2018, p. 49).
\end{abstract}

Conforme destacam Miterhof e Pereira (2018), bancos públicos de desenvolvimento, ou apenas, Bancos de Desenvolvimento (BD), existem em diversos países, incluindo desenvolvidos, como Alemanha, Coreia do Sul e Japão. Desde a última crise financeira internacional, que teve início no ano de 2007, os BD voltaram à tona como instrumento de atuação contracíclica, de forma a complementar o sistema de crédito comercial e o mercado de capitais.

Sobre esse destaque aos Bancos de Desenvolvimento, os autores explicam ainda:

\begin{abstract}
O diagnóstico é que as finanças privadas frequentemente não conseguem atuar com o perfil de risco e o horizonte de longo prazo requeridos por algumas atividades cruciais ao desenvolvimento, bem como não oferecem solução alocativamente eficiente para a intermediação financeira na presença de atividades intensivas em externalidades, mesmo no caso de mercados profundos e maduros (MITERHOF e PEREIRA, 2018, p. 879-880).
\end{abstract}

É nessa esteira que Miterhof e Pereira (2018) salientam que, no Brasil, o BNDES é considerado uma instituição singular, pois além de mitigar a severidade atípica da restrição de crédito de longo prazo, tem uma carteira de ativos compatível com as dos principais bancos de desenvolvimento nacionais do mundo, quando essa comparação leva em conta o PIB de cada país.

Para Oliveira (2015), o BNDES não teve, em sua origem, o objetivo de financiar a reconstrução da economia de um país arrasado pela guerra, como foi o caso de bancos de países europeus ou do Banco Mundial, mas decorre da necessidade de fortalecer a economia interna, de financiar em períodos longos a infraestrutura necessária ao crescimento industrial. A emergência do desenvolvimento que elevou o Brasil à sexta economia do mundo no ano de 2012 ocorreu a partir de uma reestruturação produtiva, econômica e financeira consolidada nos anos 2000, período de grandes projetos de investimentos, realizados pelo setor público e 
também pela iniciativa privada, os quais receberam financiamentos do Banco Nacional de Desenvolvimento (OLIVEIRA, 2015).

\title{
2.2 O BANCO NACIONAL DE DESENVOLVIMENTO ECONÔMICO E SOCIAL (BNDES)
}

O Banco Nacional de Desenvolvimento Econômico e Social (BNDES) foi criado pela Lei $\mathrm{n}^{\circ} 1.628$ de 20 de junho de 1.952, no governo do Presidente Getúlio Vargas, para fomentar diversos setores da economia, com a finalidade de ajudar o País a se desenvolver. À época, tinha a natureza de autarquia e, conforme descrito na lei, denominava-se Banco Nacional do Desenvolvimento Econômico. Mas, em 1971, com a promulgação da Lei no 5.662, sua natureza jurídica passou a ser de Empresa Pública.

Em sua origem, o então BNDE representou uma dupla inovação: em relação ao objetivo, ao qual implementou financiamentos de longo prazo, até então inexistente ou raros; e, em segundo lugar, em sua forma de atuação, com critérios técnicos superiores na avaliação dos projetos submetidos e no acompanhamento daqueles aprovados (IEDI, 2018).

Para Santos (2018), o BNDES desempenhou um importante papel na consolidação da indústria brasileira, principalmente em relação aos bens de base nos anos 1950 e em bens de capital no início dos anos 1970. O autor salienta que a instituição teve participação na formulação e na execução do Plano de Metas e no II Plano Nacional de Desenvolvimento.

Veja-se, ainda, o que afirma o mesmo autor sobre a atuação do banco:

\begin{abstract}
Até meados dos anos 1960, grande parte de seus desembolsos foi destinada a empresas estatais, com reorientação nos governos militares, que deram ênfase a empresas privadas. Entre os anos 1980 e 1990, o banco sentiu a crise econômica e a incapacidade de manutenção do Estado desenvolvimentista, cabendo ao BNDES o papel de gestor da privatização e de fomentador da inserção das empresas locais no comércio internacional. No final do governo FHC, o banco passou por uma nova reorientação estratégica, que foi fortalecida e aprofundada nos dois governos Lula (SANTOS, 2018, p. 126)
\end{abstract}

Dessa forma, no início dos anos 2000, o banco assumiu uma posição importante na concentração e centralização de capitais, atuou na subscrição de capitais em bolsa de valores de empresas nacionais, bem como apoiou a realização de investimentos (SANTOS, 2018).

Conforme salienta Oliveira (2015), o BNDES encerrou a primeira década do século XXI com financiamentos superiores aos concedidos por renomados bancos internacionais de fomento. Ademais, representa um importante instrumento para a concretização das políticas 
econômicas de desenvolvimento nacional, uma vez que por meio dele existe a disciplina do crédito no mercado, principalmente onde ocorre falha da atuação privada (MORETTINI; NASCIMENTO, 2018). Interessante, ainda, destacar que o banco integra um sistema, conforme representado abaixo:

FIGURA 1 - Sistema BNDES

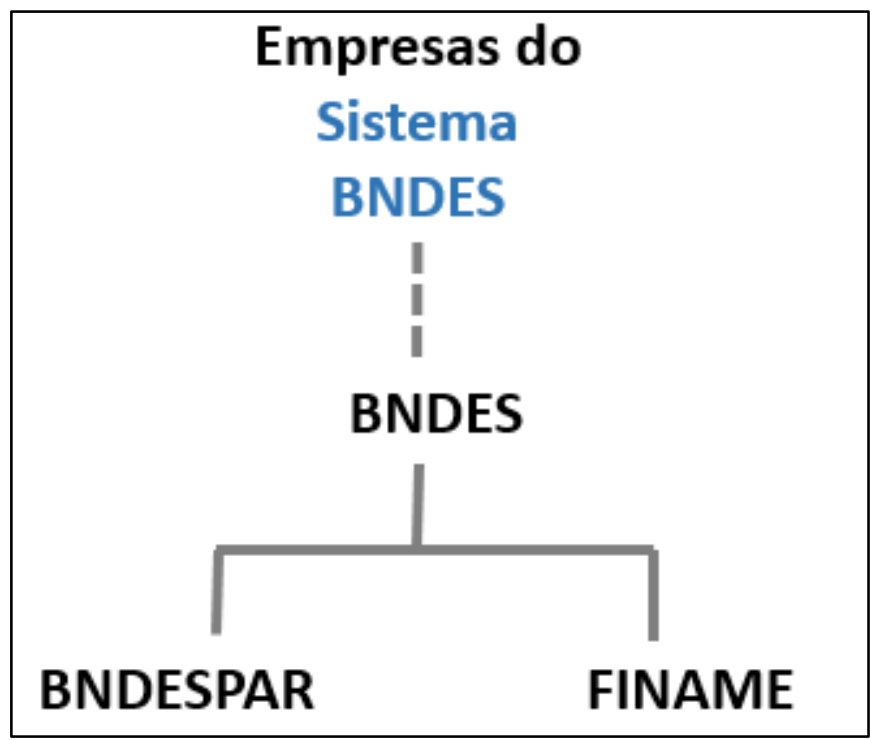

Fonte: adaptado de BNDES (2019a)

Nota-se que o BNDES possui duas subsidiárias: BNDESPAR e FINAME. A primeira se dedica ao fomento, investindo em Valores Mobiliários no Mercado de Capitais e a segunda dedica-se ao financiamento à produção e à comercialização de máquinas e equipamentos. Juntos, os três formam o denominado Sistema BNDES (BNDES, 2019a)

\subsection{FISCALIZAÇÃO DO BNDES}

O BNDES é controlado pelo Governo Federal, que detém a totalidade de suas ações, as quais compõem o capital social subscrito. A supervisão das atividades do banco é exercida pelo Ministério da Economia, que regula e orienta essas atividades por meio das seguintes unidades: Comissão de Valores Mobiliários, Conselho Monetário Nacional, Secretaria do Tesouro Nacional, Secretaria de Coordenação e Governança das Empresas Estatais, Secretaria da Receita Federal do Brasil e Superintendência de Seguros Privados (BNDES, 2019b). 
Anote-se o que consta no sítio eletrônico do BNDES sobre os Processos de Contas Anuais:

\begin{abstract}
[d]evido à natureza de suas atividades, o BNDES deve prestar contas anualmente aos órgãos de controle, evidenciando a boa e a correta aplicação dos recursos públicos, em conformidade com as normas às quais está submetido e o desempenho de sua gestão.

Objetivando a transparência deste processo e em atendimento à Portaria $\mathrm{N}^{\circ} 262$ da CGU, de 30.08.2005, estão disponíveis na internet os Relatórios de Gestão do BNDES, de suas subsidiárias integrais e dos fundos administrados FND e FGPC. Os Relatórios de Gestão são parte integrante das Prestações de Contas e apresentam as metas estabelecidas, as ações realizadas e os resultados alcançados ao longo do exercício. Sua elaboração está de acordo com as diretrizes estabelecidas nos normativos expedidos pelo Tribunal de Contas da União e pela Controladoria Geral da União.

A partir de 2018, com o intuito de promover maior accountability, o TCU decidiu adotar, para a Prestação de Contas Anual, as diretrizes da estrutura internacional de relato integrado para elaboração do relatório de gestão pelas unidades prestadoras de contas (UPC). Nessa perspectiva, esse documento precisa seguir a diretriz de clareza, mediante o uso de linguagem simples e de imagens visuais, de modo a transformar informações complexas em relatórios facilmente compreensíveis. Para atingir essas diretrizes, integrou-se o Relatório de Gestão ao Relatório Anual Integrado. (BNDES, 2019c)
\end{abstract}

Para tanto, a atividade fiscalizadora do banco é exercida pelo: a) Congresso Nacional, que recebe e emite pareceres sobre relatório dos financiamentos do BNDES que utilizam recursos do Tesouro Nacional, além de ter a prerrogativa de solicitar ao TCU a realização de auditorias e inspeções no banco; b) Banco Central, que regula e supervisiona a atuação do BNDES, determinando procedimentos e regras de operação, além de receber e analisar as demonstrações financeiras e de apurar e divulgar a Taxa de Longo Prazo (TLP); c) Tribunal de Contas da União, que recebe, analisa e julga a prestação de contas dos administradores do BNDES, solicita informações de seu interesse, realiza auditorias, avalia a legalidade de contratação e aposentadoria dos empregados do banco e fiscaliza a aplicação de recursos da União. d) Controladoria-Geral da União, que fiscaliza e avalia a execução de programas do governo, além de realizar orientação técnica e avaliar o trabalho da auditoria interna do BNDES; também realiza auditorias e avalia a gestão dos administradores do banco (BNDES, 2019b)

Esse controle e fiscalização são de grande importância para que haja lisura nas operações do banco, bem como para que eventuais correições sejam implementadas em operações que colidam com seus interesses. 


\subsection{FONTES DE RECURSOS DO BNDES}

Os recursos do BNDES são provenientes de diversas fontes, entre as quais fontes governamentais, como os fundos FAT e PIS-PASEP, além dos recursos provenientes do Tesouro Nacional, que perfizeram mais de $71 \%$ do total de recursos do banco em setembro de 2019 (BNDES, 2019d). O Gráfico 1 demonstra a origem dos recursos.

GRÁFICO 1 - Origem dos recursos do BNDES

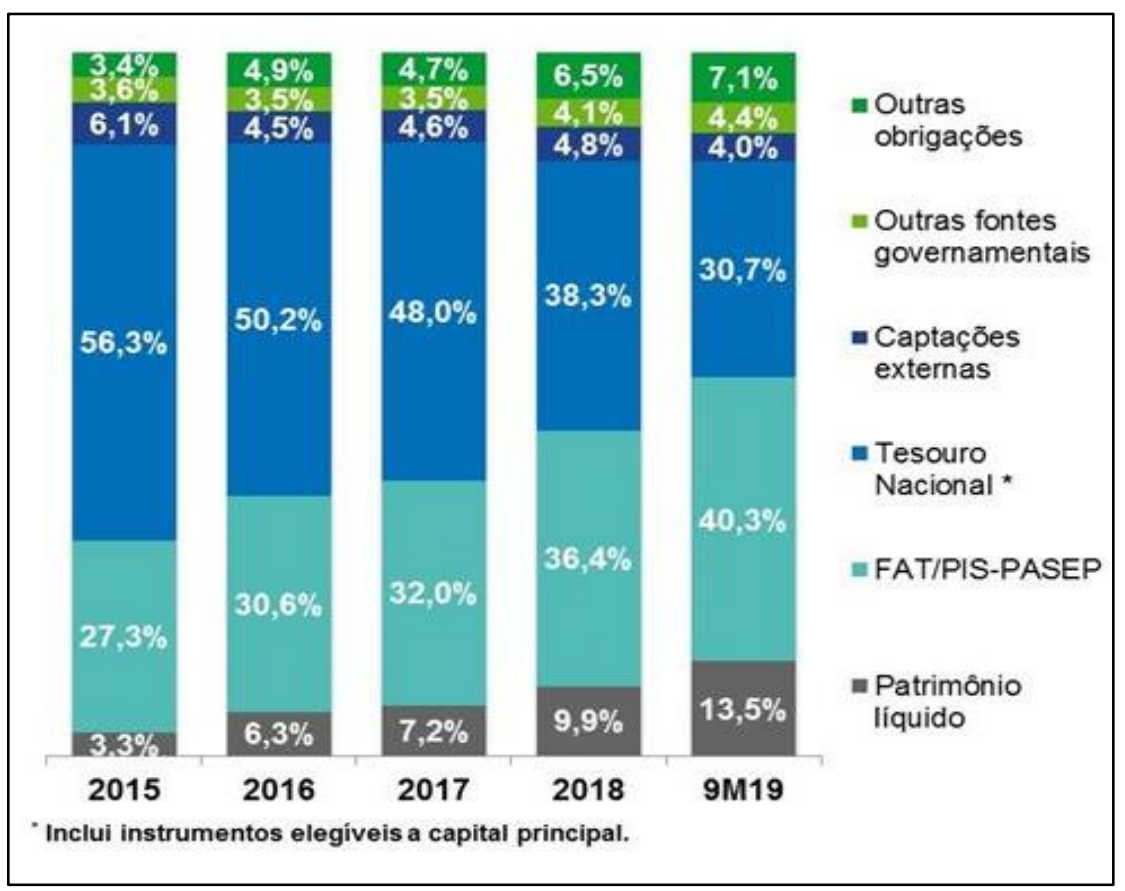

Fonte: BNDES (2019d)

As demais fontes citadas no gráfico são provenientes de recursos de outras fontes governamentais, captações no exterior, outras obrigações e o patrimônio líquido do banco, este último totalizando R \$ 100,9 bilhões até setembro de 2019. Dentre as fontes governamentais podemos elencar: a) Fundo da Marinha Mercante, cuja finalidade é prover recursos para o desenvolvimento da Marinha Mercante Nacional e para a construção de navios para a Marinha do Brasil; b) Fundo de investimento do Fundo de Garantia do Tempo de Serviço, cujos recursos captados foram destinados a projetos de construção, reforma, ampliação ou implantação de empreendimentos de infraestrutura em rodovias, portos, hidrovias, ferrovias, energia, saneamento e aeroportos; c) Fundo de Garantia do Tempo de Serviço, referente a títulos 
públicos federais junto ao FGTS. Já as outras obrigações, referem-se a emissões públicas de debêntures pela BNDESPAR e às letras financeiras (BNDES, 2019d).

Em relação às captações externas, desde 1953, o banco capta recursos no exterior por meio de operações de emissão de bonds e, desde 1972, capta recursos por meio de empréstimos junto a organismos multilaterais, agências governamentais e outras instituições (BNDES, 2019d).

Lado outro, para Oliveira (2015), que analisou os indicadores do banco entre 2007 e 2011, o aporte do Tesouro Nacional ao BNDES saltou de R $\$ 13$ bilhões para mais de R $\$ 310$ bilhões no período. Segundo a autora, esse montante, somado ao importe advindo de arrecadação do fundo dos trabalhadores, sofre críticas de diversos analistas, os quais argumentam que deveriam existir critérios mais amplos para a concessão de créditos, não baseados apenas no lucro a ser retornado pelos investimentos. A autora assevera ainda que o governo contrai dívidas para financiar o banco, e, consequentemente, essas dívidas financiam os créditos que serão concedidos por ele, cuja maior parte é destinada a empresas de grande porte, inclusive privadas (OLIVEIRA, 2015).

Nesse sentido, veja-se o que afirmam Morettini e Nascimento (2018, p. 373):

[s]e em um primeiro momento a emissão de títulos ao BNDES não impacta a dívida líquida do setor público, já que é contabilizada apenas como receita em um regime de caixa, ela aumenta muito a dívida bruta. Por sua vez, o subsídio creditício concedido pelo Tesouro Nacional, o qual é oriundo do custo de captação, é classificado no orçamento como 'Variações Financeiras', o que afeta as contas públicas apenas pelo critério 'abaixo da linha', o qual exclui as estatais financeiras como o BNDES, escondendo o resultado incremental do banco em função das operações de crédito viabilizadas pelos empréstimos do Tesouro Nacional, ou seja, também não interfere no resultado primário. Já os subsídios financeiros concedidos ao PSI entram como 'Subsídios e Subvenções Econômicas', fazendo com o seu pagamento afete o resultado primário.

Além da crítica dos autores à forma como são contabilizados esses aportes, os recursos destinados ao BNDES pelo Tesouro resultam numa remuneração ao erário inferior ao custo de captação desse crédito. Isso porque os empréstimos ao banco são remunerados com taxas “próximas à TJLP, inferiores às taxas de juros pagas pelo Tesouro (acima da Selic) em relação aos títulos da dívida pública emitidos para sustentar as operações de crédito, sendo que a diferença entre essas taxas se torna despesa para o Tesouro na forma de subsídio" (MORETTINI; NASCIMENTO, 2018)

Entretanto, entendem os autores que esses aportes são importantes para a manutenção dos investimentos de longo prazo, inclusive porque têm o potencial de "estabilizar as expectativas dos agentes econômicos para a manutenção da realização de investimentos, transformando 
incertezas em riscos" (MORETTINI; NASCIMENTO, 2018, p. 395). Todavia, é salutar analisar para quem e para onde esses empréstimos estão sendo direcionados.

\section{OS REQUISITOS PARA A CONCESSÃO DE EMPRÉSTIMOS PELO BNDES}

O BNDES oferece diversos produtos, os quais definem as regras gerais de financiamento. Esses produtos podem ser divididos em linhas de financiamento com condições específicas para cada tipo de cliente (empresas, empresários individuais, entidades ou órgãos públicos, clubes, sindicatos etc), a depender também de seu objetivo (BNDES, 2019f)

Conforme o BNDES (2019e), para pedir um financiamento junto ao banco, o interessado deve atender os seguintes requisitos mínimos: a) estar em dia com as obrigações fiscais, tributárias e sociais; b) apresentar cadastro satisfatório; c) ter capacidade de pagamento; d) dispor de garantias suficientes para cobertura do risco da operação; e) não estar em regime de recuperação de crédito; f) atender a legislação relativa à importação, no caso de financiamento para a importação de máquinas e equipamentos; f) cumprir a legislação ambiental.

Além disso, não podem se beneficiar de crédito junto ao BNDES as pessoas físicas ou jurídicas, bem como seus respectivos controladores, que se enquadrarem nas hipóteses a seguir: a) possuam inadimplemento com o Sistema BNDES; b) sejam responsáveis por título protestado (salvo se for, a critério do BNDES, justificado o protesto ocorrido); c) constem em processo judicial que, a critério do BNDES, possa comprometer a capacidade de cumprimento de suas obrigações perante o BNDES; d) tenham apontamentos cadastrais indicando inadimplemento contumaz ou restrições à sua idoneidade; e) estejam em processo de falência, concordata ou recuperação judicial ou extrajudicial (BNDES, 2019e).

Esses requisitos objetivos, além de nortear as escolhas e estabelecer os riscos para o banco, certamente contribuem, ainda que minimamente, para que haja um lastro de confiança no cumprimento das obrigações financeiras, bem como para que o investimento gere algum impacto no desenvolvimento, mormente em cenários de crises e incertezas no campo econômico, como o que estamos atravessando no momento.

Destarte, o banco classifica os interessados em função do porte, conforme receita operacional bruta (ROB), a fim de adequar a oferta de linhas, programas e condições específicas. E considera prioritário o apoio às micro, pequenas e médias empresas, oferecendo condições especiais com o intuito principal de facilitar o acesso destas empresas ao crédito. (BNDES, 2019e). 
Sendo assim, interessante destacar que, ao priorizar o crédito às empresas de pequeno porte, o banco atende ao princípio esculpido no inciso IX do art. 170 da Constituição Federal, o qual trata da ordem econômica e estabelece o "tratamento favorecido para as empresas brasileiras de capital nacional de pequeno porte". Um exemplo dessa abordagem prioritária pode ser vislumbrada nas operações relacionadas ao Cartão BNDES. Veremos a seguir os critérios para essa operação.

\subsection{CARTÃO BNDES}

O Cartão BNDES consiste num crédito pré-aprovado para financiar investimentos de micro, pequenas e médias empresas, cujo faturamento bruto anual não exceda $\mathrm{R} \$ 90$ milhões, desde que sediadas no Brasil e exerçam atividade econômica compatíveis com as Políticas Operacionais e de Crédito do BNDES e que estejam em dia com o FGTS, RAIS e tributos federais. Trata-se de um crédito com taxas de juros mais atrativas que as do mercado, com financiamento automático em até 48 meses (BNDES, 2019e).

A respeito dos critérios para concessão, afirmam Corseuil et al (2019, p.10):

[o] Cartão BNDES é uma linha de crédito, do tipo pré-aprovada, voltada para o financiamento de aquisição de bens e serviços por MPMEs. Criado em 2002, o novo produto financeiro do BNDES representava uma mudança de paradigma na forma de financiamento para empresas de menor porte, baseada na ideia de fornecer para pessoas jurídicas um cartão de crédito, assim como os existentes para pessoas físicas.

Nesse contexto, o interessado pode solicitar o cartão pela internet e preencher uma proposta, que posteriormente deverá ser entregue num dos bancos emissores do cartão (Bradesco, Banco Brasil, dentre outros) (BNDES, 2019g). Podem ser adquiridos com o cartão itens e serviços de diversos setores, dentre computadores, materiais de construção civil, caminhões, autopeças etc, totalizando cerca de 140 mil itens, cujo limite de crédito é atribuído pelo banco emissor, mediante análise de crédito, não superior a um milhão de reais (BNDES, $2019 \mathrm{~g})$.

Sobre a relação com o banco emissor, Corseuil et al (2019, p.10) salientam:

[o] BNDES atuou historicamente com MPMEs por meio da modalidade indireta de financiamento, que se baseava no uso da rede bancária comercial existente no território para alcançar as empresas de menor porte espalhadas pelo país. Nessa modalidade, os agentes financeiros são repassadores de crédito do BNDES e atuam à medida que um potencial tomador solicita financiamento de uma das linhas de crédito do Banco. Os bancos comerciais são os responsáveis pela análise da operação e pelo risco de crédito. 
Essa operação buscava aumentar a capilaridade do BNDES por meio da utilização de serviços dos demais bancos (Corseuil et al, 2019). Para os autores, o interessado poderá ter um Cartão BNDES por bandeira em cada banco emissor, com respectivos limites, os quais podem ser somados para realização das compras até o limite máximo de $\mathrm{R} \$ 1$ milhão (Corseuil et al, 2019).

O Gráfico 2 demonstra o crescimento dos financiamentos envolvendo o cartão BNDES no período 2006-2012.

GRÁFICO 2 - Crescimentos dos financiamentos envolvendo o cartão BNDES no período de 2006 a 2012

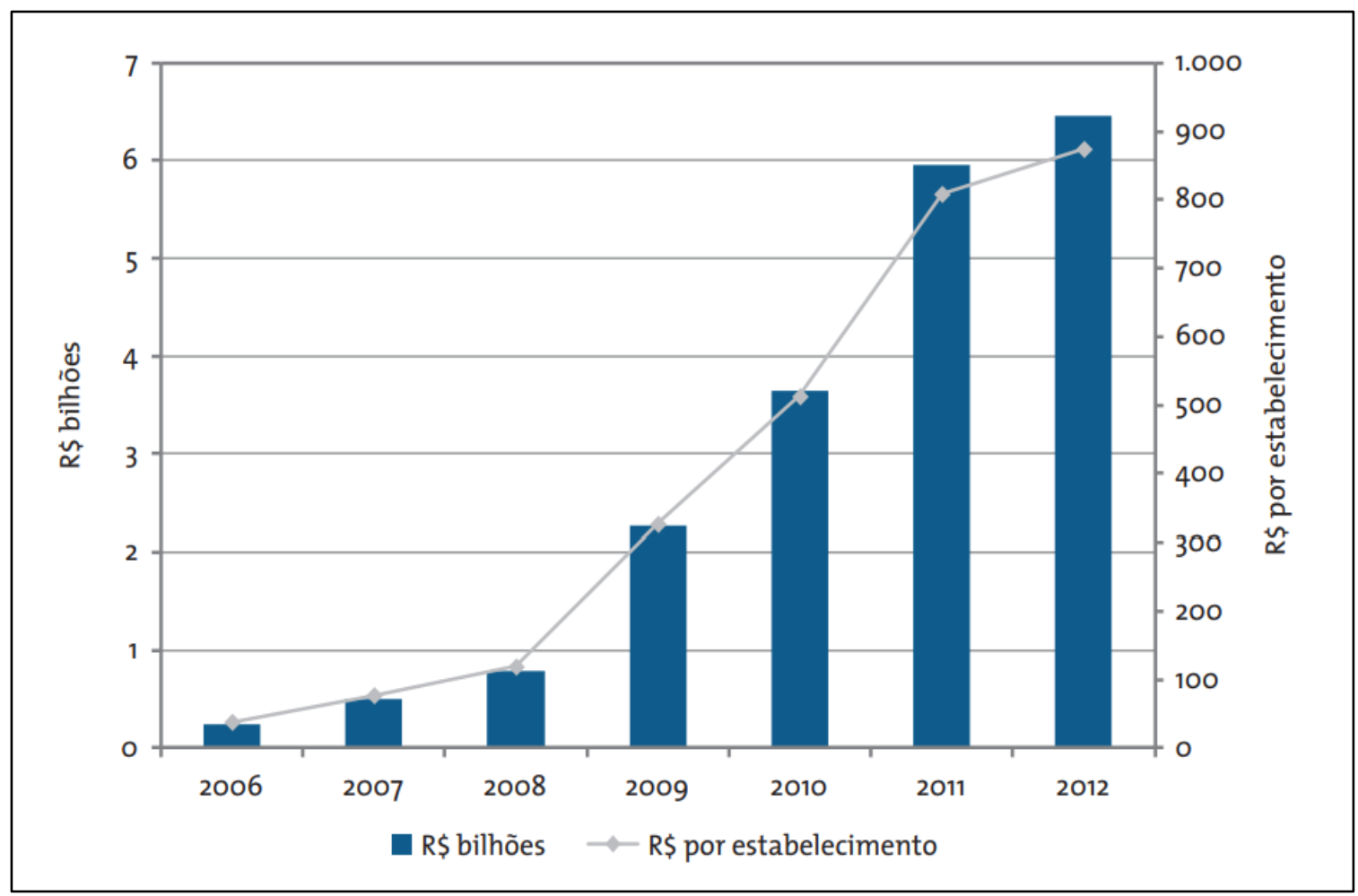

Fonte: adaptado de Corseuil et al (2019)

Do gráfico é possível observar que os valores financiados cresceram exponencialmente, principalmente a partir de 2009, quando os financiamentos saltaram da marca $\mathrm{R} \$ 2$ para 6 bilhões, o que demonstra a aceitação do produto pelas empresas (Corseuil et al, 2019). 


\section{ALGUMAS CONSIDERAÇÕES SOBRE O IMPACTO DO BNDES NO DESENVOLVIMENTO}

Conforme afirma Santos (2018), a partir de 2003, os desembolsos do BNDES aumentaram significativamente, a fim de contribuir para a ampliação e modernização do aparelho produtivo nacional, a inserção no mercado internacional em alguns ramos, a formação de grandes grupos nacionais, a distribuição mais equânime das atividades econômicas e a internacionalização produtiva.

Galdi e Sousa (2018), após investigar a reação do mercado diante dos créditos subsidiários pelo BNDES, concluíram que os resultados encontrados confirmaram a hipótese de sua pesquisa, de forma que os testes estatísticos indicaram que "a média dos retornos anormais obtidos pelas empresas que contrataram crédito junto ao BNDES foi positiva e significativa, num período de três dias em torno da data da contratação". (GALDI; SOUSA, 2018, p. 53)

O Gráfico 3 demonstra o valor financiado com o produto "Cartão BNDES” por região do país: 
GRÁFICO 3 - Valor financiado com o produto “Cartão BNDES” por região do país

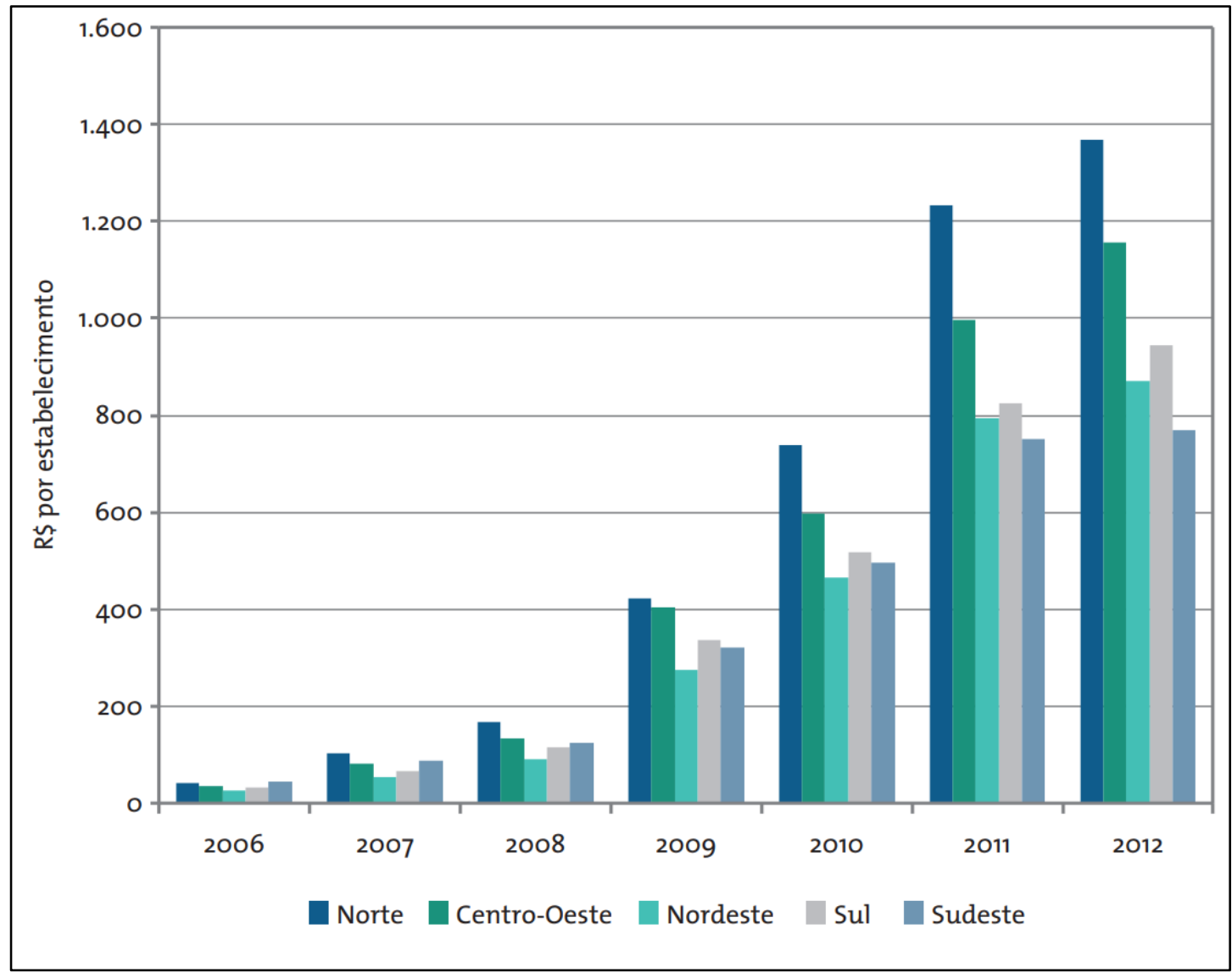

Fonte: Corseuil et al (2019)

No gráfico 3 é possível observar que o maior volume de financiamentos está concentrado nas regiões Norte e Centro-Oeste e não apenas nas regiões mais industrializadas; além disso, os financiamentos estão crescendo em ambas as regiões (Corseuil et al, 2019). Todos esses fatores demonstram que o Cartão BNDES é um importante instrumento de crédito à disposição das empresas, contribuindo efetivamente para o desenvolvimento econômico, não apenas em âmbito regional.

Outrossim, conforme Relatório de Efetividade do BNDES (2017), entre 2015 e 2016, para cada R\$ 1 milhão "aplicado pelo BNDES em atividades com alta influência sobre o emprego, foram estimados 20,2 postos de trabalho associados à sua implementação" (PINTO et al, 2018, p.121). E não só:

[p]ara se ter uma ideia da magnitude das estimativas de emprego do MGE, o Gráfico 13 mostra a evolução da razão (em percentual) entre as estimativas de emprego dos desembolsos do BNDES e o estoque de emprego formal do Brasil, usando dados da Rais. Entre 2014 e 2016, houve destruição de cerca de 3,5 milhões de postos de trabalho no Brasil. Entretanto, a queda dos desembolsos do BNDES no mesmo período engendrou uma queda significativa dos empregos estimados. Assim, em 2015 
os trabalhadores associados aos investimentos do BNDES representavam 5,2\% de toda a força de trabalho formal no país e em 2016 esse percentual chega a cerca de $3 \%$. Espera-se que uma ascensão do volume de recursos aportados pelo BNDES no futuro contribua de forma significativa para a retomada do crescimento e a superação da crise e que a instituição possa ter níveis mais expressivos de participação no emprego. Outra possibilidade é intensificar o apoio a setores com alto potencial de geração de emprego e o apoio a empresas de menor porte, o que, por sua vez, pode trazer um efeito sobre a formalização do trabalho (PINTO et al, 2018, p. 121)

Obviamente, o desemprego não está ligado apenas aos desembolsos, mas o estudo é interessante, pois consegue fazer uma ligação verossímil com o assunto. Nessa seara, o estudo apresentado por Alves, Botelho e Fernandes (2018, p. 124-125), no qual buscou-se avaliar os impactos dos recursos disponibilizados pelo produto FINAME (BNDES), nas "firmas industriais" brasileiras, destaca que "considerando a variedade de modelos ajustados, o acesso ao crédito subsidiado apresenta impactos positivos sobre a taxa de criação de emprego, a taxa de crescimento do pessoal ocupado e a taxa de crescimento da renda".

Veja-se parte de suas conclusões:

[a] análise da taxa de crescimento do pessoal ocupado técnico visa capturar mudanças tecnológicas advindas do acesso aos créditos subsidiados do BNDES. Neste caso, novamente, encontramos efeitos positivos e estatisticamente significantes dos financiamentos, os quais, entretanto, perdem intensidade após 2008. Atribuímos este decréscimo de impacto ao provável afrouxamento dos critérios de seleção de firmas para os programas de financiamento durante o período expansivo. Nossos achados reforçam os argumentos em favor da existência de efeitos crowding-out.

Os resultados do teste de Chow mostram que os efeitos do tratamento antes e depois de 2008 são estatisticamente diferentes. De forma geral, podemos corroborar nossa hipótese de que o aumento na oferta de crédito subsidiado resultou no declínio dos impactos esperados sobre as firmas, ainda que tais impactos se mantenham positivos. (ALVES; BOTELHO; FERNANDES, 2018, p. 124-125)

Os autores afirmam ainda que, de forma geral, podem corroborar sua hipótese de que o "aumento na oferta de crédito subsidiado resultou no declínio dos impactos esperados sobre as firmas, ainda que tais impactos se mantenham positivos" (ALVES, BOTELHO; FERNANDES, 2018, p. 124-125).

Por outro lado, é interessante salientar que nem todas as pesquisas realizadas apresentaram resultados satisfatórios. Na pesquisa elaborada por Moraes e Wanke (2019), em que os autores buscaram o impacto de bancos de desenvolvimento sobre o desempenho produtivo da indústria siderúrgica, o resultado encontrado foi negativo, no sentido de que, embora a pesquisa tenha suas limitações, no recorte estabelecido, não se identificou impacto positivo dos desembolsos do BNDES na eficiência das empresas que receberam esses aportes. 
Em outra pesquisa, Goldszmidt et al (2018) analisaram o impacto do microcrédito no Brasil (produto do BNDES), entrevistando mais de 2 mil beneficiários de microcréditos, que teriam recebido esse aporte nos primeiros trimestres de 2016 ou 2017. Não foram encontrados impactos significativos de microcrédito na renda, emprego geração, acesso a crédito, formalização de negócios, acesso a bens e serviços e bem-estar subjetivo no Nordeste ou no Sul.

Os estudos mencionados têm suas peculiaridades e abrangem determinados seguimentos da economia e produtos específicos do banco. Mesmo assim, é importante demonstrar que nem todos os aportes tiveram grandes impactos no desenvolvimento regional.

Nesse contexto, Schlickmann (2016) faz uma crítica aos aportes realizados pelo banco a determinadas indústrias, como a de químicos e pneus no Brasil. O autor questiona se o BNDES adotou a política das "campeãs nacionais" para direcionar financiamentos a determinadas empresas, bem como questiona se seria possível prestar contas dessas políticas de financiamento.

A preocupação de Schlickmann faz muito sentido, pois, obviamente, os recursos públicos devem ser destinados de forma proba a empresas que tem potencial para implementar o desenvolvimento regional, bem como buscar o desenvolvimento do País.

Em resposta aos anseios da sociedade pela transparência das instituições, recentemente, o Poder Público disponibilizou uma interessante ferramenta de pesquisa: um sítio eletrônico denominado "aberto" do BNDES. Nele é possível observar relatórios sobre a "caixa-preta", “operação lava-jato", "os R 500 bi”, dentre outros casos que deram destaque à atuação do banco; além de divulgar um conjunto de ações para dialogar com a sociedade, repensar e assumir pontos a serem melhorados na gestão, como a criação da Corregedoria interna, Plano de Dados Abertos, contratação de auditoria externa forense etc, o que demonstra ao menos o interesse da atual gestão na transparência da instituição.

\section{CONCLUSÃO}

Neste trabalho, inicialmente foi explanado que bancos de desenvolvimento não existem apenas no Brasil, mas sim em diversos países, incluindo os desenvolvidos. Nesse sentido, o principal banco de desenvolvimento do Brasil é o BNDES; empresa pública, controlada pelo Governo Federal, cuja supervisão de suas atividades é exercida pelo Ministério da Economia.

O objetivo primordial do banco é apoiar programas, projetos, obras e serviços que se 
relacionem com o desenvolvimento econômico e social do País; atuando sob a fiscalização do Tribunal de Contas da União, Controladoria Geral da União, Banco Central do Brasil, dentre outros, o que, a nosso sentir, demonstra que é significativa a preocupação do Poder Público com a lisura de suas operações.

Foi demonstrado que os recursos do BNDES são originários de diversas fontes, dentre elas o FAT, o PIS-PASEP, aportes do Tesouro Nacional, dentre outros. No entanto, em relação a esse último, críticas têm surgido, tendo em vista que, segundo estimativas, a remuneração desses aportes do Tesouro é menor do que os custos de captação dos recursos, o que é um dado muito preocupante; por essa razão entendemos que esse tipo de participação deve ser gradualmente extinto, bem como sejam priorizadas novas fontes mais sustentáveis para a "saúde financeira" do banco.

Quanto aos impactos dos desembolsos na economia, foram apresentados resultados de pesquisas que demonstram que as empresas que obtiveram créditos do BNDES tiveram respostas positivas desses investimentos. Corroborando essa afirmação, conforme relatório de efetividade do banco, para cada $\mathrm{R} \$ 1$ milhão aplicado em determinadas atividades, foram estimados 20,2 postos de trabalho. Obviamente essa constatação não serve a todos os setores da economia, mas é um dado importante para que seja possível constatar a efetividade desses desembolsos.

Outrossim, a pesquisa foi efetiva ao cumprir os objetivos (dentro do recorte proposto), apresentando um panorama sobre a atuação do banco, bem como ao abordar o problema, demonstrando-se os requisitos para a concessão dos empréstimos, bem como aspectos sobre a influência desses recursos no desenvolvimento econômico.

Por fim, ressalta-se que é de fundamental importância que as políticas do banco no atual contexto econômico valorizem a livre iniciativa, mas priorizando a concessão de aportes financeiros para empresas que apresentem condições de gerar um retorno significativo, não apenas financeiro para a instituição, mas principalmente contribuir para o desenvolvimento econômico e social, com a geração de empregos e estímulo a economia.

Para tanto, entendemos que um mapeamento de áreas estratégicas para o desenvolvimento, como saúde, ciência, indústria, dentre outras, aliado ao fomento e aceleração de empresas que operam esses seguimentos pode contribuir de forma considerável para que importantes operações sejam implementadas no cenário nacional. 


\section{REFERÊNCIAS}

ALBUQUERQUE, Breno Emerenciano; GRIMALDI, Daniel da Silva; GIAMBIAGI, Fabio; BARBOZA, Ricardo de Menezes. Os bancos de desenvolvimento e o papel do BNDES. Brasília: BNDES, 2018. Disponível em: <https://web.bndes.gov.br/bib/jspui/bitstream/1408/15920/1/PRLiv214075_Os\%20bancos\%2 0de\%20desenvolvimento_compl_P.pdf>. Acesso em: 21 nov. 2019.

ALVES, Patrick; BOTELHO, Davi; FERNANDES, Jessica. Avaliação de impacto dos financiamentos do BNDES sobre as firmas industriais brasileiras no período pós-crise. In: NEGRI, João Alberto de; ARAÚJO, Bruno César; BACELETTE, Ricardo (Orgs). Financiamento do desenvolvimento no Brasil. Brasília: IPEA, 2018. Disponível em: <http://repositorio.ipea.gov.br/bitstream/11058/8820/1/Fiinanciamento_do_desenvolvimento _no_Brasil.pdf>. Acesso em 27 dez. 2019

ARAÚJO, Bruno Cesar; BACELETTE, Ricardo. O perfil e o papel exercido pelos bancos de desenvolvimento nacionais: análises comparativas internacionais. In: NEGRI, João Alberto de; ARAÚJO, Bruno César; BACELETTE, Ricardo (Orgs). Financiamento do desenvolvimento no Brasil. Brasília: IPEA, 2018.

ATAÍDE, Camille da Silva Azevedo; SOARES, Dennis Verbicaro. O crédito como objeto de tensão qualificada na relação de consumo e a necessidade de prevenção do superendividamento. Revista de Direito da UFGRS, Porto Alegre, n. 36, p. 73-89, vol. esp., out. 2017.

BNDES. Banco Nacional de Desenvolvimento Econômico e Social. Estrutura do Sistema BNDES. Rio de Janeiro: BNDES, 2019a. Disponível em: 〈https://bit.ly/2QTstZ>. Acesso em: 08 dez. 2019.

BNDES. Banco Nacional de Desenvolvimento Econômico e Social. Relação com órgãos governamentais. Rio de Janeiro: BNDES, 2019b. Disponível em: <https://www.bndes.gov.br/wps/portal/site/home/quem-somos/governanca-controle/estruturade-gestao-do-sistema-bndes/relacao-orgaos-governamentais>. Acesso em: 08 dez. 2019.

BNDES. Banco Nacional de Desenvolvimento Econômico e Social. Processos de contas anuais. Rio de Janeiro: BNDES, 2019c. Disponível em: <https://bit.ly/2Qkr6Dl>. Acesso em: 08 dez. 2019.

BNDES. Banco Nacional de Desenvolvimento Econômico e Social. Fontes de recursos. Rio de Janeiro: BNDES, 2019d. Disponível em: <https://www.bndes.gov.br/wps/portal/site/home/relacoes-com-investidores/fontes-derecursos>. Acesso em: 08 dez. 2019.

BNDES. Banco Nacional de Desenvolvimento Econômico e Social. Quem pode ser cliente. Rio de Janeiro: $\quad$ BNDES, 2019e. Disponível em: <https://www.bndes.gov.br/wps/portal/site/home/financiamento/guia/quem-pode-ser-cliente>. Acesso em: 08 dez. 2019. 
BNDES. Banco Nacional de Desenvolvimento Econômico e Social. Instrumentos de financiamento. Rio de Janeiro: BNDES, 2019f. Disponível em: 〈https://bit.ly/35ibAvX〉. Acesso em: 08 dez. 2019.

BNDES. Banco Nacional de Desenvolvimento Econômico e Social. Cartão BNDES. Rio de Janeiro: BNDES, 2019g. Disponível em: <https://www.cartaobndes.gov.br/cartaobndes/PaginasCartao/Noticia.asp?Acao=CV\&cod=1 $\&$ Exibe $=$ S $>$. Acesso em: 08 dez. 2019.

BNDES. Banco Nacional de Desenvolvimento Econômico e Social. Quem somos. Rio de Janeiro: BNDES, 2020a. Disponível em: <https://www.bndes.gov.br/wps/portal/site/home/quem-somos>. Acesso em: 25 maio 2020.

BNDES. Banco Nacional de Desenvolvimento Econômico e Social. BNDES contra os efeitos do coronavírus. Rio de Janeiro: BNDES, 2020b. Disponível em: <https://www.bndes.gov.br/wps/portal/site/home/bndes-contra-coronavirus>. Acesso em: 27 maio 2020.

CORSEUIL, Carlos Henrique Leite; ROITMAN, Fábio Brener; ULYSSEA Gabriel; MACHADO, Luciano. Uma análise do perfil e da dinâmica das empresas que usam o Cartão BNDES. Brasília: BNDES, 2019. Disponível em: <https://web.bndes.gov.br/bib/jspui/bitstream/1408/18300/1/PRFol_Analise\%20do\%20perfil $\% 20$ das $\% 20$ empresas\%20que\%20usam\%20o\%20Cartao\%20BNDES_compl.pdf>. Acesso em: 21 dez. 2019.

GOLDSZMIDT, Rafael; BEHR, Patrick; ZUCCO, Cesar; LENZ, Anna-Katharina; FARIAS, Lauro Emilio Gonzalez; VALDIVIA, Martin. Microcredit Impacts: Evidence from a Largescale Observational Study in Brazil. Rio de Janeiro: EBAPE, 2018. Disponível em: $<$ http://rafaelgoldszmidt.com/wp-content/uploads/2019/03/Goldszmidt-et-al.-2018-

Microcredit-Impacts-Evidence-from-a-Large-scale-Observational-Study-in-Brazil-1.pdf $>$. Acesso em: 29 dez. 2019.

IEDI. Instituto de Estudos para o Desenvolvimento Industrial. Carta IEDI n. 834 - BNDES do futuro, um banco voltado para o desenvolvimento. São Paulo: IEDI. 2018. Disponível em: <https://iedi.org.br/cartas/carta_iedi_n_834.html>. Acesso em: 25 dez. 2019.

MORETTINI, Felipe Tadeu Ribeiro; NASCIMENTO, Jefferson Rodrigo do. O impacto na dívida pública ocasionado por meio das transferências realizadas pelo Tesouro Nacional ao BNDES a partir de 2009: uma análise funcional no contexto da crise econômico-financeira internacional. Revista de Direito Econômico e Socioambiental, Curitiba, v. 9, n. 3, p. 366-401, set./dez. 2018.

MORAES, Ricardo Kalil; WANKE, Peter Fernandes. Impacto do BNDES na eficiência da indústria siderúrgica: aplicação do modelo Malmquist de dois estágios. Cadernos EBAPE.BR, Rio de Janeiro, v. 17, n.2, p. 229-246, jun. 2019.

OLIVEIRA, Claudia de. O papel do banco nacional de desenvolvimento econômico e social como financiador dos investimentos de longo prazo: o caso do grupo ebx - Brasil. Redes Revista do Desenvolvimento Regional, Santa Cruz do Sul, v. 20, n. 1, p. 194 - 213, jan./abr. 2015. 
PEREIRA, Thiago Rabelo; MITERHOF, Marcelo Trindade. O Papel do BNDES e o financiamento do desenvolvimento: considerações sobre a antecipação dos empréstimos do Tesouro Nacional e a criação da TLP. Economia e Sociedade, Campinas, v. 27, n. 3, p. 875908, dez. 2018.

PINTO, Arthur de Rezende et al. Relatório de efetividade 2017: efetividade para um novo ciclo de crescimento econômico. Rio de Janeiro: Banco Nacional de Desenvolvimento Econômico e Social, 2018. Disponível em: <https://web.bndes.gov.br/bib/jspui/handle/1408/15145>. Acesso em: 29 dez. 2019.

SANTOS, Leandro. BNDES: internacionalização de empresas e o subimperialismo brasileiro. Geousp - Espaço e Tempo, v. 22, n. 1, p. 115-137, 2018.

SOUSA, Anderson Fioresi de; GALDI, Fernando Caio. Estrutura de capital e custo de capital subsidiado no Brasil: influência no valor das ações das empresas. Revista Contemporânea de Contabilidade, Florianópolis, v. 15, n. 34, p. 42-57, jan./mar. 2018.

SCHLICKMANN, Paulo Henrique. A distribuição geográfica dos aportes do BNDES para a indústria do plástico, da borracha e da química no brasil. Boletim Goiano de Geografia. Goiânia, v. 36, n. 3, p. 463-481, set./dez. 2016.

TIMM, Luciano Benetti. O CDC e os Serviços Bancários no Brasil. Revista da Faculdade de Direito da UFRGS, v. 19, mar. 2001.

\section{DADOS DA PUBLICAÇÃO}

Categoria: artigo submetido ao double-blind review.

Recebido em: 18/09/2020.

Aceito em: 30/11/2021. 